УДК 81 '23

DOI: $10.33184 /$ bulletin-bsu-2021.3.51

\title{
ОСОБЕННОСТИ СОВРЕМЕННОГО МАСС-МЕДИЙНОГО ТЕКСТА
}

\author{
() А. С. Титлова, Е. В. Полякова* \\ Башкирский государственный университет \\ Россия, Республика Башкортостан, 450076 г. Уфа, ул. Заки Валиди, 32. \\ Тел./факс: +7 (347) 2299652. \\ *Email:fotodarr@mail.ru
}

\begin{abstract}
Статья посвящена изучению такой особенности онлайн-коммуникации, как анонимность, и ее влияния на восприятие интернет-текста. В статье рассматривается нарушение социальных норм, что ведет к проявлению ненормативных и агрессивных коммуникативных тенденций и, как следствие, шеймингу. Данная работа освещает такой тип шейминга, как эйджизм, то есть дискриминацию по возрастному критерию. В качестве экспериментального материала рассматриваются реакиии пользователей (их «встречные текстыл»), набор которых является проявлением индивидуальной стратегии понимания текста конкретным реципиентом. В результате анализа материала делается вывод, что преобладающим типом реакций являются комбинированные, в состав которых входит негативная оченка.
\end{abstract}

Ключевые слова: шейминг, эйджизм, анонимность, интернет-коммуникачия, «встречный текст», психолингвистический эксперимент.

\section{Введение}

Одной из основных характеристик интернеткоммуникации является ее опосредованность, «косвенность». Отсутствие непосредственного, личного контакта предоставляет необходимые условия для анонимности пользователя и его сетевого общения. Интернет-коммуникация возможна, даже если коммуникант не указывает имени, идентифицирующего его, либо общается под вымышленным именем (никнеймом).

Анонимность сетевой коммуникации влечет за собой определенные «психологические последствия» [4, с. 372]. При предоставлении коммуникантом личных данных, пользователь осознает, что может быть узнан; в таком случае, тактики, которые он применяет при общении в сети, схожи с теми, которые характерны для него в процессе реальной, офф-лайн коммуникации. Если пользователь предпочитает при общении в сети скрыть свое реальное имя, используя вместо него вымышленный или анонимный аккаунт, то его коммуникация реализуется через отсутствие ограничений в средствах выражения и сдерживающих факторов. В такой ситуации коммуникант полностью свободен в самовыражении и раскрепощен. При этом, наряду с положительными личными качествами, проявляются и отрицательные, асоциальные, обычно подавляемые в ситуациях общения в реальной жизни [5].

Отсутствие последствий за нарушение норм, существующих в социуме, ведет к ненормативному речевому поведению и зачастую агрессии [10; 14]. Коммуникация анонимных пользователей характеризуется свободой не только высказываний, но и поступков, которые от оскорблений и использования табуированной лексики могут перерасти в угрозы и сексуальные домогательства, «т.к. риск разоблачения и личной отрицательной оценки окружающими минимален» [2, с. 63]. Участником ком- муникации игнорируются языковые табу, снимается запрет на обсценную оскорбительную лексику в адрес оппонента.

Такая свобода и вседозволенность приводит к появлению в интернет-коммуникации такого феномена, как шейминг. Под шеймингом (shaming) принято понимать дискриминацию, чаще всего вербального характера, которая заключается в критике, высмеивании, унижении людей за то, что инициатором шейминга рассматривается как недостаток, нечто постыдное и неподобающее.

По мнению психологов, причины шейминга могут быть разнообразны: от осуждаемых социумом мнений и действий до физических особенностей и бедственного материального положения. Шейминг, несомненно, является социальным феноменом, распространенным и в повседневной реальной жизни, в т.ч. Столь же несомненным нам видится и тот факт, что коммуникация с проявлениями шейминга приводит к негативным последствиям. Такое проявление дискриминации в адрес участников коммуникации наносит вред и психическому, и физическому здоровью $[1 ; 6]$.

Существует множество разновидностей шейминга: их может быть столько, сколько поводов у людей испытывать стыд самим или стыдить других.

В статье освещается такой тип шейминга, как эйджизм (ageism; age - возраст), под которым принято понимать дискриминацию по возрастному критерию. С этим феноменом могут сталкиваться как пожилые люди, к которым социум относится с пренебрежением, так и более молодое поколение, в связи с отсутствием достаточного жизненного опыта.

Несомненно, любой конфликт, являясь столкновением точек зрения, может возникнуть только в процессе коммуникативного контакта. Именно расхождение во взглядах, несовпадение мнений коммуникантов приводят к ряду речевых поступков 
участников общения, не соблюдающих социально установленные нормы коммуникации. При этом нарушаются устоявшиеся традиции ведения дискурсивной деятельности, речевое поведение обусловливается ненормативными индивидуальными характеристиками собеседников [11].

Интернет-коммуникация, несомненно, является одним из наиболее конфликтогенных типов за счет упомянутых выше особенностей такого типа общения (анонимности и опосредованному характеру коммуникации). Это, в свою очередь, приводит к высокой степени конфликтогенности интернет-текста. Далее в статье предпринимается попытка подтвердить данную гипотезу на основании методики контр-текста, или «встречного текста» [12].

Чтобы определить, как текст воспринимается и интерпретируется участниками коммуникации, не приводят ли особенности его понимания к коммуникативному конфликту, вследствие чего проявляется речевая агрессия (т.е. шейминг), в настоящей статье применяется психолингвистический метод «встречного текста», разработанный А. И. Новиковым [7]. Согласно основным принципам данного метода возможно «экспериментально исследовать сам процесс восприятия текста в его более непосредственном виде, приближенном к реальному протеканию» [7, с. 64].

Метод «встречного текста» - это эксперимент, основанный на предположении автора о том, что реципиент любого текста активен, он не просто пассивно фиксирует информацию текста, не просто отражает его содержание, но и реагирует на него, вербализуя в ответ «встречный текст», т.е. набор своих индивидуальных реакций. В реакциях реципиента проявляется выбор индивидуальной стратегии понимания, а воспринимающий информацию реципиент отображает собственное понимание смысла текста, что позволяет «судить полно и точно о внутренней стороне процесса восприятия текста» [7, с. 65.].

А. И. Новиков предполагал использование своей методики «встречного текста» в условиях контролируемого эксперимента, но ее также можно применить и в естественной среде интернеткоммуникации [9].

Тогда текстом-стимулом будет являться массмедийный текст, а «встречным текстом», то есть реакцией реципиентов, - комментарии пользователей на такой интернет-текст [13; 15]. Результаты, полученные в ходе «естественного» эксперимента, были классифицированы, количественно и качественно обработаны с учетом основных принципов метода «контр-текста» с целью выявления особенностей реакций на масс-медийный текст (включая реакции, содержащие элементы шейминга).

В качестве текста-стимула в психолингвистическом эксперименте выступил пост с новостью о том, что, спустя почти 20 лет, приступили к съемкам продолжения известного сериала «Секс в большом городе». Возраст героинь сериала в настоящий момент, согласно сюжету, 50+. Вербальная часть текста-стимула сопровождается визуальной: коллажами фотографий актрис времен первой части сериала и со съемок в настоящее время.

«Встречными текстами» для анализа реакций послужили 120 комментариев пользователей. При обработке результатов методом «встречного текста» выявлено, что большая часть реакций реципиентов представляет собой комбинированные реакции (сочетание двух или более одиночных реакций), в состав которых входит реакция оценки (отношение комментатора к информации текстастимула) [3; 8]. Реакция оценки, в свою очередь, представлена положительной и негативной оценкой. Так, комментариев с положительной оценкой 37 (31\%), негативных реакций оценки - 83 (69\%).

Приведем примеры комбинированных реакций-комментариев, содержащих положительную оценку: «Молодцы! Я только за! Женщины должны видеть, что есть жизнь после пятидесяти!», «Вооот, и в этом возрасте можно полноценно жить, а не ползти в сторону кладбища)))», «Ну какие же они красотки! В любом возрасте».

К негативным комбинированным реакциям можно отнести следующие: «Кошмар, ей-богу. Назовите тогда уж Климакс в большом городе *рукалицо*», «Че то как то... Что за печеные яблоки?:(», «Хороши! Были когда-то( Сейчас даже смотреть не буду».

\section{Заключение}

Из краткого обзора экспериментального материала видно, что большая часть комментаторов отрицательно реагирует на произошедшие с актрисами возрастные изменения, при этом позволяя себе оскорбительные высказывания на почве возраста: «не секси, а шмекси», «сморщенные секссимволы», «модные старушенции».

Таким образом, можно сделать вывод, что комментарии пользователей, содержащие элементы шейминга, преобладают, а коммуниканты позволяют себе высказывания, которые вряд ли бы использовали при личном общении, и выходят за рамки принятой в обществе нормы.

\section{ЛИТЕРАТУРА}

1. Айсина Р. М. Психологическая безопасность взрослых интернет-пользователей: анализ современных исследований // Омск: ОмГУ, 2019. №1. С. 28-38.

2. Виноградова Т. Ю. Специфика общения в интернете // Русская и сопоставительная филология: Лингвокультурологический аспект. Казань, 2004. С. 63-67.

3. Гак В. Г. Эмоции и оценки в структуре высказывания и текста // Вестник МГУ. Сер. 9. Филология. М., 1997. №3. C. $87-95$.

4. Горошко Е. И. Интернет-жанр и функционирование языка в Интернете: попытка рефлексии // Жанры речи. Саратов: Издательский центр «Наука», 2009. №6. «Жанр и язык». С. 370-389.

5. Жельвис В. И. Поле брани: сквернословие как социальная проблема. М.: Ладомир, 1997. 330 с. 
6. Леонтьев А. А. Психолингвистические особенности языка СМИ // Язык СМИ как объект междисциплинарного исследования. М.: изд-во МГУ, 2003. С. 66-88.

7. Новиков А. И. Текст и «контртекст»: две стороны процесса понимания // Вопросы психолингвистики. Текст: восприятие, понимание, интерпретация. М.: 2003. №1. С. 64-76.

8. Титлова А. С. Оценочность контртекста в виртуальном дискурсе (на примере микроблогов) // Межкультурная интракультурная коммуникация: теория и практика обучения и перевода. Мат-лы 4-й Междунар. науч.-практ. конф. Уфа, 2015. С. 381-383.

9. Титлова А. С. Об особенностях экспериментальных методов при исследовании процессов восприятия и понимания текстов микроблога // Актуальные проблемы русской и сопоставительной филологии: теория и практика. Мат-лы Междунар. научно-практ. конф. Уфа, 2016. С. 403-407.
10. Филиппов К. А. Лингвистика текста: курс лекций. СПб.: изд-во С.-Петербургского ун-та, 2003. 336 с.

11. Фрумкина Р. М. Психолингвистика: что мы делаем, когда говорим и думаем. Препринт WP6/2004/04. М.: ГУ ВШЭ, 2004. 24 c.

12. Чернявская В. Е. Поликодовое пространство текста: лингвосемантическая парадигма языкознания // Язык в парадигмах гуманитарного знания: XXI в. СПб.: 2009. С. 23-35.

13. Шаховский В. И. Типы значений эмотивной лексики // ВЯ, №4. М.: Наука, 1994. С. 20-26.

14. Шведова Н. Ю. Грамматика современного русского литературного языка. М.: Наука, 1970. 767 с.

15. Шевякова Л. П. Основные формы общения в Интернете и их особенности // Образование. Коммуникация. Ценности. (Проблемы, дискуссии, перспективы) / под ред. С. И. Дудника. СПб: Санкт-Петербургское философское общество, 2004. C. 26-29.

Поступила в редакциию 03.09.2021 2. 
DOI: $10.33184 /$ bulletin-bsu-2021.3.51

\title{
CHARACTERISTIC FEATURES OF CONTEMPORARY MASS MEDIA TEXT
}

\author{
(C) A. S. Titlova, E. V. Polyakova*
}

Bashkir State University

32 Zaki Validi Street, 450076 Ufa, Republic of Bashkortostan, Russia.

Phone: +7 (347) 2299652.

*Email:fotodarr@mail.ru

This article is devoted to the study of such a feature of online communication as anonymity and its impact on the characteristics of the perception of Internet text, as well as mediation as the main characteristics of Internet communication. The authors of the article study the violation of social norms, which leads to the manifestation of abnormal and aggressive communicative tendencies and, as a result, shaming. Shaming is seen as discrimination, most often of a verbal nature, which consists in criticism, ridicule, humiliation of people for what the initiator of shaming considers as a disadvantage, something shameful and inappropriate. This work highlights such a type of shaming as ageism, that is, age discrimination. This phenomenon can be encountered by both the elderly, whom society treats with neglect, and the younger generation, due to the lack of sufficient life experience. As experimental material, the authors consider the reactions of users (their "counter texts"), the set of which is a manifestation of the individual strategy of understanding the text by a specific recipient. The results obtained in the course of the "natural" experiment were classified, quantitatively and qualitatively processed, taking into account the basic principles of the "counter-text" method in order to identify the features of reactions to a mass-media text (including reactions containing shaming elements). As a result of the analysis of the material, it is concluded that the predominant type of reactions are combined reactions, which include a negative assessment.

Keywords: shaming, ageism, anonymity, Internet communication, counter text, psycholinguistic experiment.

Published in Russian. Do not hesitate to contact us at bulletin_bsu@mail.ru if you need translation of the article.

\section{REFERENCES}

1. Aisina R. M. Omsk: OmGU, 2019. No. 1. Pp. 28-38.

2. Vinogradova T. Yu. Russkaya i sopostavitel'naya filologiya: Lingvokul'turologicheskii aspekt. Kazan', 2004. Pp. 63-67.

3. Gak V. G. Vestnik MGU. Ser. 9. Filologiya. Moscow, 1997. No. 3. Pp. 87-95.

4. Goroshko E. I. Zhanry rechi. Saratov: Izdatel'skii tsentr «Nauka», 2009. No. 6. «Zhanr i yazyk». Pp. 370-389.

5. Zhel'vis V. I. Pole brani: skvernoslovie kak sotsial'naya problema [The battlefield: foul language as a social problem]. Moscow: Ladomir, 1997.

6. Leont'ev A. A. Yazyk SMI kak ob"ekt mezhdistsiplinarnogo issledovaniya. Moscow: izd-vo MGU, 2003. Pp. 66-88.

7. Novikov A. I. Voprosy psikholingvistiki. Tekst: vospriyatie, ponimanie, interpretatsiya. Moscow: 2003. No. 1. Pp. 64-76.

8. Titlova A. S. Mezhkul'turnaya - intrakul'turnaya kommunikatsiya: teoriya i praktika obucheniya i perevoda. Mat-ly 4-i Mezhdunar. nauch.-prakt. konf. Ufa, 2015. Pp. 381-383.

9. Titlova A. S. Aktual'nye problemy russkoi i sopostavitel'noi filologii: teoriya i praktika. Mat-ly Mezhdunar. nauchno-prakt. konf. Ufa, 2016. Pp. 403-407.

10. Filippov K. A. Lingvistika teksta: kurs lektsii [Text linguistics: course of lectures]. Saint Petersburg: izd-vo S.-Peterburgskogo un-ta, 2003.

11. Frumkina R. M. Psikholingvistika: chto my delaem, kogda govorim i dumaem [Psycholinguistics: what we do when we speak and think]. Preprint WP6/2004/04. Moscow: GU VShE, 2004.

12. Chernyavskaya V. E. Yazyk v paradigmakh gumanitarnogo znaniya: XXI v. Saint Petersburg: 2009. Pp. 23-35.

13. Shakhovskii V. I. VYa, No. 4. Moscow: Nauka, 1994. Pp. 20-26.

14. Shvedova N. Yu. Grammatika sovremennogo russkogo literaturnogo yazyka [Grammar of modern Russian literary language]. Moscow: Nauka, 1970.

15. Shevyakova L. P. Obrazovanie. Kommunikatsiya. Tsennosti. (Problemy, diskussii, perspektivy). Ed. S. I. Dudnika. Saint Petersburg: Sankt-Peterburgskoe filosofskoe obshchestvo, 2004. Pp. 26-29. 